\title{
RE-GENERATING KINESTHETIC HISTORY: THE DYNAMICS OF \\ TRANSMITTING WILLIAM FORSYTHE'S ONE FLAT THING, REPRODUCED
}

\author{
Heather Young Reed
}

\section{ABSTRACT}

Reconstructing, remounting, restaging, and reworking are terms that are used to describe the process of choreographic transmission. Typically today, dances are transmitted through notated scores, video recordings, and the kinesthetic history of previous cast members. This article illuminates the liminal space between score, screen, and stage by analyzing the process of transmitting William Forsythe's One Flat Thing, reproduced (2000) to a group of students at The Juilliard School in 2013. Conclusions drawn from the case study challenge traditional notions of reconstruction and restaging and suggest 're-generation' as an alternative term to describe the process of preserving and transmitting contemporary dance works.

(Keywords: Regeneration, Restaging, Forsythe, Kinesthetic History)

\footnotetext{
Although there are certainly merits to written scores and video recordings in the documentation of many dance forms, the twenty-first century has given rise to a contemporary choreographic movement that demands a reconsideration of the topic of dance preservation and transmission. Pushing at the boundaries of structure and form that have traditionally been associated with classical dance practices, contemporary artists often explore additional performative and choreographic approaches, resulting in works that are in a constant state of flux. Experimentation with concepts such as improvisation
} 
and audience participation, as well as the incorporation of various technologies, contribute to the sense of plurality often characteristic of contemporary dance. As a result, modes of dance preservation in the form of fixed tangible records, designed to encapsulate complete dances, no longer seem capable of capturing the porous features of a contemporary work. My intention is not to dismiss the notion of the written archive, nor in any way to de-value the practice of dance reconstruction and its contribution to both historical and choreographic discourse. Instead, my aim is to consider an alternative approach to the practice of sharing, or passing on, dances. I propose that, as contemporary choreography continues to evolve, we must look toward a method of dance preservation that more closely resembles that which it is intended to preserve, one that considers issues such as multiplicity and fluidity, thus allowing an opportunity to reconstruct the present, rather than the past. It is on this basis that I suggest the regeneration of kinesthetic history as an additional methodological approach toward dance preservation, one that continues to legitimize the role of embodiment, to embrace notions of subjectivity, and to recognize the dancers' agency in historiographical discourse.

The possibility that movement can be written into a dancer's bodily memory challenges the notion of ephemerality, and suggests that dance can exist in some way beyond Marcia Siegel's often quoted "perpetual vanishing point."' This dichotomy between elusiveness and endurance has been a recurring theme in dance preservation discourse. ${ }^{2}$ Although traditional modes of documentation, such as written notation and video, suggest that dances can exist in visual, symbolic, and linguistic forms, these tokens are purely referential to that which they represent, as opposed to that which they actually are. Does the dance exist on the stage, or in the studio? Written into a score? Captured 
through a lens? Or viewed on a screen? Does it exist in the bodies of the performers? Or in the mind/body of the choreographer? Once we are better able to understand the ontological locality of a work, then we can more closely interrogate the ways in which that work can be transmitted between dancers.

Dancer/choreographer and scholar, Jeff Friedman, describes the challenges posed by current modes of dance preservation and supposes that dance's lack of sufficient documentation is in part a residual effect of dance's ephemeral nature combined with the practicalities of live performance. He suggests that "We might obtain remedies for these difficulties at the level of methodology, that is, identifying documentation strategies commensurate with dance that adequately record live performance.... Consequently, dance calls for a documentary method that is also alive: embodied, contingent and temporal." ${ }^{\text {F }}$ Following Friedman's suggestion, it is logical that the method of recreating a dance work should closely resemble the method that was employed to create the work in the first place. I have chosen to explore this issue through a case study that considers the ways in which various modes of documentation functioned as archival sites in a restaging of William Forsythe's One Flat Thing, reproduced $(O F T r, 2000)$ at The Juilliard School in 2013. The work was restaged as part of Juilliard's annual repertoire concert," which also featured Four Brubeck Pieces (1984) by Murray Louis and Sunset (1983) by Paul Taylor. When restaging $O F T r$ at Juilliard the process involved a combination of source materials including a written score, video recordings, a series of graphic animations made available through an online resource entitled Synchronous Objects, and what I refer to as

\footnotetext{
* The choice of the term repertoire, rather than repertory is inspired here by Diana Taylor's The Archive and the Repertoire (Durham, NC: Duke University Press, 2003).
} 
the kinesthetic history of the original cast member who set the piece. I recognize that these types of source materials are not dissimilar to those used in most dance reconstructions, and it is for this reason that a discussion of the ontological locality of a piece of choreography is warranted. In the case of OFTr, the multiplicity of archival sites reiterates the question of which of these sites can be considered home to the most reliable record of the work, and illuminates how kinesthetic history functioned as a mode of corporeal transmission when restaging the dance. My focus on the role of kinesthetic history in the re-generation of $O F T r$ builds on the perspectives of scholars such as Sally Ann Ness, Tomie Hahn, and Gabriele Brandstetter, who suggest that gestural movement becomes inscribed in a dancer's body through corporeal experience, therefore creating an embodied record of a dance's existence. ${ }^{4}$ My primary aims are to foreground the dancer's body as a site of inscription and to consider its role as a mode of sharing choreographic information between past and present cast members. In doing so, I will highlight the ways in which the liminal space between record and performance was re-generated through the subjective, interpretative, and dynamic experience of the participants.

I approached this research from the perspective of a dancer, as opposed to that of a notator or archivist. Dance historians are broadly aware of the roles of written notation and video documentation in the context of dance preservation discourse. What is less clear are the various ways in which the records produced from such modes of preservation act to illuminate the liminal spaces between record and performance. It is for this reason that I have chosen to interrogate the topic of dance preservation with a specific focus on recreating a dance, rather than for the purpose of documenting a record of it. More specifically, where the choreographic process involved the embodied 
inscription of movement material into the kinesthetic memory of a dancer, the restaging process should similarly evoke those memories in a manner that facilitates their reinscription into a new cast member's body. In theory, both written notation and video documentation are capable of evoking the original cast member's kinesthetic memory in this way. However, I suggest that, in practice, embodied memory serves as a more reliable record for re-generating a dance. This is not a new concept by any means. For centuries dancing masters, practitioners and historians have relied upon the kinesthetic transmission of embodied memory in the practice of sharing and passing on dances. Susan Foster explains that, during the time of dancing master Thoinot Arbeau, "notation was construed as preserving dances and guiding instruction, but dancing still required personal interaction," ${ }^{5}$ and at the Dance ReConstructed Conference in 1992 Stuart Hodes suggested, "dance is ruled by an ancient paradigm, that of oral history; its works are preserved by being passed directly from one dancer to another." ${ }^{\prime 6}$ Similarly, Valerie Preston-Dunlop harkens back to her embodied experience when discussing her recreations of Rudolf Laban's "lost" works by saying that she was "able to engage with the archival evidence with a muscle memory and perspective informed by four years of close practice with Laban." Although Preston-Dunlop acknowledges the importance of kinesthetic memory to the recreation process, she also admits that such processes are in a constant state of flux. In her discussion of recreation, she explains, "dances are allographic by nature; even the most rigid choreography changes with each performance, each casting, and each venue. A choreographer has to choose when to minimize change and when to embrace it." ${ }^{8}$ In this way, regardless of the terminology used, all reconstructions co-exist on the same continuum of regenerative practices. Some sit on the 
end of the spectrum that calls for accuracy and exactitude, while others occupy the space that allows for more 'openness' to the work's variability. ${ }^{\dagger}$ What all regenerations have in common is their need for some sort of reliance on kinesthetic experience.

\section{Re-Generating Kinesthetic History As A Methodological Approach}

Both written notation and video, in their various forms, attempt to inscribe the ephemeral, to arrest movement and gesture in a manner that fixes them to a particular form, time, and space. While these types of records are undeniably useful in many scenarios, such objects of documentation remain devoid of actual physicality and continue to limit the agency of the dancing body. Operating as a counterpart to oral history, and borrowing theoretical concepts from contemporary historiography, existential phenomenology, and ethnography, my concept of kinesthetic history is largely based on the notion that lived experiences become inscribed into an individual's embodied memory, therefore being preserved in the form of a kinesthetic record. The recollection and retrieval of such memories is then activated through re-embodying the inscribed material, at which point it can be visually, verbally, and kinesthetically transmitted through a collective embodied experience between dancers to re-generate the dance.

Kinesthetic history acts as a mode of remembering and recalling the physical sensation of being present in the moment of a performance, even if that memory is referential to something that is long gone. According to Brandstetter, "choreography, as

\footnotetext{
†I refer here to Sarah Rubidge's use of the term 'open work' in "Identity and the Open Work," Stephanie Jordan, ed. Preservation Politics: Dance Revived, Reconstructed, Remade (London: Dance Books Ltd., 2000), 205-15.
} 
the writing of and about movement, as preserved in memory, thus always includes something of a requiem." ${ }^{, 9}$ Referring to the impermanence and ephemerality of choreography, Brandstetter goes on, "William Forsythe has been engaged by these questions more, perhaps, than any other contemporary choreographer." However, the rigor exercised by his stagers and the faith Forsythe seems to have in their bodily memory of the company's repertoire indicate that he is well aware of the formidable power of kinesthetic inscription and transmission.

As an artist who is famously against the traditional concept of score writing for the purpose of preservation, Forsythe prefers to explore alternative modes of writing of and about dance, modes that celebrate the transience of contemporary culture. He and his dancers have built up a repertoire of works that pay homage to the conceptual understanding of dance as an evolutionary art form, and by doing so the artistic ethos of The Forsythe Company represents a creative process that is in a constant state of flux. To continuously construct and deconstruct various choreographic paradigms, Forsythe has had to rely upon the collective kinesthetic history of his dancers. Much of the Forsythian repertoire is interwoven with newer works borrowing thematic and dramaturgical information from older ones, and in order to work in this way the company has developed a specific kinesthetic culture through the continuous bodily inscription of their choreographic practices. In doing so, Forsythe and his dancers have remained at the forefront of philosophical, theoretical, and methodological ways of thinking about movement.

In The Archive and the Repertoire, performance studies scholar Diana Taylor calls for dance scholars to make a shift towards this model, which has been the 
cornerstone of Forsythe's artistic invention for some time: "By shifting the focus from written to embodied culture, from the discursive to the performatic, we need to shift our methodologies. Instead of focusing on patterns of cultural expression in terms of texts and narratives, we might think about them as scenarios that do not reduce gestures and embodied practices to narrative description. ${ }^{10}$ For Taylor, there is a distinct difference between the archive and the repertoire. The archive refers to a written document and the repertoire represents an embodied experience, which becomes embedded in the individual or collective memories of its participants. She suggests that, unlike the archive, "the repertoire allows for an alternative perspective on historical processes," thus enabling a body of knowledge that is open to interrogation and interpretation. ${ }^{11}$ When explained in this way, the term repertoire indicates an apt choice made by dance companies to describe their collection of works. A company's repertoire of dances suggests a different meaning than their archive of resources. The former suggests a body of kinesthetic experiences that is very much alive and contingent on the embodied memories of previous cast members, whereas the latter conjures the image of a library, storeroom, or hard drive that houses the company's collection of static records. The repertoire refers not only to a compilation of a choreographer or company's body of work, but also to the collective repertoire of experiences embodied by those who have performed them.

In discussions about preserving and restaging a company's works, this notion of the repertoire becomes ever more important to an analysis of the ways in which works are transmitted between dancers. Once a dance has been inscribed into the embodied memory of a dancer through the repetitive process of rehearsal and performance, how then is that 
information shared with a new cast? Taylor suggests, "live performance can never be captured or transmitted through the archive"; but rather by embodied memory, "because it is alive, exceeds the archive's ability to capture it." ${ }^{\prime 2}$ Of course, the counter argument to Taylor's position questions the permanency of the embodied repertoire, suggesting that the archive provides a more stable and enduring account of a dance, which is otherwise vulnerable to being lost when those with embodied experience are no longer able to pass it on. This is a valid criticism of kinesthetic history, and particularly relevant to the discussion of dance preservation. My concept of re-generation suggests that the work should be open to being created anew through the bodies of different cast members, and I acknowledge that written notation and video recordings are suitable alternatives in cases where live transmission is not possible. This notion calls for an intensive examination of the ways in which the acquired and shared inscription of kinesthetic history operates as a mode of transmitting choreographic information and re-generating a dance.

\section{Contextualizing Corporeal Inscription, Transmission And Re-Generation}

The vigor of corporeally inscribed kinesthetic history versus the static quality of a notated score seems aptly captured in Sally Ann Ness's comparison of "writing down" versus

"writing up" dance ethnography. ${ }^{13}$ She suggests that the process of "writing up" the ethnographic record as a monograph often dilutes the authenticity of the original participatory experience, which was captured through "writing down" field notes. Ness's ethnographic comparison can be used to contrast what is gained in the act of writing down a lived choreographic experience through embodied inscription versus what is lost 
in the act of writing up a traditional notated score. Writing down, or inscribing, choreographic information into a moving body supposes that the repetitive act of performing a sequence of movements solidifies that kinesthetic experience as an embodied memory. Conversely, the process of writing up a score or editing a video removes the element of embodiment from the scenario and suggests that the record has lost a certain amount of immediacy: "the ethnographer's memory and otherwise physical figure are thus dissociated in the classical score as these two aspects of the self are sequenced in the process of text-making." ${ }^{14}$ Seen in this way, the post-experiential process of creating a score or video actually distances the record even farther from any lived experience of the dance itself.

When comparing embodied memory with a written or recorded document, questions about permanence are inevitable. Of course, a written score or film gives the illusion of permanence because each is a tangible object that can be viewed repeatedly and scrutinized at length, but in actuality they represent only one version of the work, rather than the work in its entirety. Dance thrives as a movement practice that balances precariously between permanence and impermanence. Once a dance has been performed it becomes permanently embedded in the dancer's kinesthetic memory, but it will never be performed the same way twice, meaning that the inscribed record will be in a constant state of transformation. This dichotomy raises questions of how a practice that is so fragile can be preserved in the form of a permanent record, or even if it should be. As Ness articulates,

The relationship of dance to the airy "host" into which it is typically expressed, a "material" so light that the idea of cutting into its "depths" produces only images 
of fleeting trace forms or ghostly trajectories, is critical to the discourse that asserts for dance a semiotics that is essentially transient. This is how the vanishing and ephemeral character of dance's gestures is often justified. ${ }^{15}$

Ness expresses the common notion of dance's impermanence and thus demonstrates how this leads to overlooking the body as the actual site of inscription. She admits that, when "understood in this way, dance becomes the antithesis of inscription." 16 Teetering on the edge of ephemerality, the endurance of a dance actually relies entirely on its inscription into the dancer's bodily memory. As Brandstetter explains, "choreography is a form of writing along the boundary between presence and no longer being there: an inscription of the memory of that moving body whose presence cannot otherwise be maintained." ${ }^{17}$ If we subscribe to Brandstetter's way of thinking about choreography, it is impossible to perceive a record of a dance as anything other than the embodied memory of the dancer(s) performing the work. The dance is therefore indivisible from the dancer, and any sort of retrievable history of the dance in question lives in the body of the dancer who brought that work to life.

Issues relating to the retrieval and transmission of embodied memories that have been kinesthetically inscribed into the bodies of those who have performed the work become clearer during the process of re-generating a dance. Many practitioners, notators, and historians agree that there is no better way to teach a piece of choreography than through human interaction in the dance studio. Consider the following excerpt from a document about dance preservation published by the Dance Heritage Coalition in 2004: “"Watch me.' 'Let me show you.' 'Not that way ... this way.' From toe to toe, from hand to hand, from eye to eye, dance, more than any other of the performing arts, has been 
transmitted through time by human chains of dancers, choreographers, and others involved in its creation and performance." 18 This quote exemplifies the way in which most dances are passed on, with the expert practitioner sharing choreographic information through verbal cues, visual demonstrations, and tactile feedback with new cast members. For this mode of transmission to be possible, there are two imperative conditions: the participants must be working together in a shared space, and the teacher must rely on his or her own embodied memory of performing the work. In this way, the practice of corporeal transmission is reliant not only on visual, verbal, and tactile cues, but also on a kinesthetic energy that has the capacity to shift and change with the flow of the process. For example, one of the most obvious advantages of learning a dance from someone who has previously performed it is the opportunity for the learners to ask questions. Questioning opens up a dialogue between past and present performers, affording reciprocal exchange in the re-inscription process. Taylor explains, "the repertoire requires presence: people participate in the production and reproduction of knowledge by 'being there,' being a part of the transmission." 19 This transmission to which Taylor refers is indicative of the reciprocity of the repertoire, as it exists both in the embodied memory of the original cast member and the newly acquired kinesthetic sensibility of the learner.

I posit that kinesthetic history transmits movement information through visual, verbal, and tactile cues, all of which promote kinesthetic awareness and celebrate the embodied nature of dance. Echoing the sentiments of Friedman and Taylor, I suggest that kinesthetic history offers a methodological shift that approaches dance preservation as regeneration by using the same logic that is commensurate with dance practice itself. Re- 
generation mirrors the initial process of generating movement material, which often involves exploratory negotiations between visual, verbal, tactile, and kinesthetic cues.

Therefore, if we are to consider the terminology that is often used to describe the practice of transmitting dances, the terms reconstruction, restaging, remounting, or reworking no longer seem appropriate for contemporary dance. This case study describes the multi-layered and dynamic process of transmitting $O F T r$ to the students at Juilliard and suggests a consideration of the term re-generation when discussing the process of sharing the original cast member's kinesthetic experience with a new generation of dancers. For the students, the aim was not simply to learn the steps and re-perform the dance, but to learn to embody an entirely new way of working as an ensemble and a new way of thinking about choreographic relationships. OFTr is based on a contrapuntal system of cues and alignments, and elements of the work are designed to respond to a rigorous set of improvisational directives. Therefore, the lesson was in learning to make informed decisions and to be responsible for the ways in which those decisions affected the rest of the group. The dancers were encouraged to infuse their own personalities, choices, and impromptu decisions into the work, while remaining cognizant of the fact that the momentum of the entire piece hinged upon their ability to function as a cohesive unit. According to Taylor, "as opposed to the supposedly stable objects in the archive, the actions that are the repertoire do not remain the same. The repertoire both keeps and transforms choreographies of meaning." ${ }^{20}$ In this way, the term 're-generation' recognizes the constant evolution of this contemporary work while also embracing the notion that the work will shift dramatically in response to the individual dancers who 
perform it. Re-generation celebrates those elements of plurality and multiplicity that are central to the repertoire of contemporary choreographic practices.

\section{Re-Generating Oftr: A Case Study}

OFTr is an intricately complex work, and the task of restaging it is a daunting one. Since The Forsythe Company premiered the work in 2000, OFTr had been restaged twice before coming to Juilliard, and in both instances, a group of dancers from The Forsythe Company were called upon to restage the work, based on the original version set for fourteen dancers. At Juilliard, the work was restaged based on the version of OFTr that is shown on Synchronous Objects, which included seventeen dancers as opposed to the original fourteen. The Juilliard restaging marked the first time Synchronous Objects was used as a restaging tool and also the first time only one cast member, Christopher Roman, assumed the task of restaging OFTr. As is the case with most reconstructions, Roman had a variety of tools at his disposal to aid him with the process of teaching the dance to the students: access to video footage of the dance, the digital scoring tools made available through Synchronous Objects, his own personal hand-written score, and of course his embodied memory of co-creating and dancing in more than one hundred performances of the work. Notably, the written score and digital scoring applications were rarely used and the majority of the material was shared through live transmission and visual cues picked up from the videos.

The primary choreographic structure of $O F T r$ is based on the principle of counterpoint, which Forsythe describes as "a field of action in which the intermittent and irregular coincidence of attributes between organizational elements produces an ordered 
interplay." 21 The movement material comprises twenty-five structured phrases, which the dancers refer to as "themes." These themes are repeated and reconfigured throughout the duration of the work and are considered to be set material, meaning that they do not change between iterations of the work. A number of improvisational tasks are also interspersed throughout the piece, whereby the dancers make impromptu choices in response to predetermined directives. Choreographic tasks as allocated by Forsythe (or the assigned stager) are applied to the original thematic material, resulting in variations of the theme that differ in such ways as temporal quality and directional flow. Although much of the movement material is set, the temporal aspect of the dance is constantly fluctuating in response to the improvised moments. The musical accompaniment, which was composed by Thom Willems, is most accurately described as a soundscape comprising a selection of twenty-four pre-recorded sounds. Much of the soundscape is improvisational and the sounds are mixed in real-time in response to the cues given by the dancers. Complicating the work even further is the fact that the dance is performed on and around twenty free-standing tables. These tables are moved around the space by the dancers, and provide additional surfaces for movement to occur.

\section{Transmission of OFTr Through Digital and Demonstrative Visual Cues}

The visual transmission of $O F T r$ occurred primarily through two modes of observation. The first of these was through the video of the work that is available to view on the Synchronous Objects website, and the second was through the lived experience of watching Roman's physical demonstrations in the rehearsals. It is difficult to say which was more effective in terms of the transmission of movement material because they 
occurred simultaneously throughout the process. The video on Synchronous Objects can be viewed either from the front or from a bird's eye perspective, which proved to be extremely useful. The additional camera angle allowed Roman and the dancers to view much of the complex maneuvering, which occurred both on top of and behind the tables, that is otherwise obstructed by the traditional frontal view. Despite the obvious advantages of the video recording, it did present a number of practical complications that hindered the restaging process. Reactions by Roman and the students indicated that the most frustrating and common hindrance was that the video did not always work as it should. Because of issues such as poor internet signal and slow connection speed, there were many times when the group was gathered around the screen to watch a segment of the video, only to have it freeze. Roman and the production team spent some time trying to troubleshoot the issue, but often the video was abandoned for the far more immediate option of physically demonstrating the information. For the most part, the video was used to give a general overview of the specific section of the piece being worked on and to point out the cues and alignments the dancers needed to be aware of. Because there is so much happening at one time in $O F T r$, this continuous process of show-and-tell-thenmove proved to be extremely efficient.

The video undoubtedly contributed to the speed at which the actual choreographic construction of the work occurred. The students' access to the video on their own devices allowed them to learn the work on their own time and come to rehearsals already knowing much of the movement material that was to be taught that day in rehearsal. But, as Roman explains, this was both an advantage and a drawback: 
One thing that was challenging for me was the inability for me to physically set all seventeen parts on my own, piece by piece, and give everybody direct information. Because the piece is so heavily counterpointed, it is impossible to teach all the parts at once in relationship to that counterpoint. Instead, I had to allow people to learn it partially from the video and that kind of tinged a bit, because I had to give up control. I just didn't have any other choice but to give it up for that moment. They are so expert at learning from video now because they are the YouTube, iPad generation and that was helpful, but I've had to go back and shave off the individual interpretations that appeared in that video and give them additional information to what appears in that 2-dimensional thing they are seeing on the screen. ${ }^{22}$

The individual interpretations referred to by Roman are the subtle nuances and personality quirks that the original cast members embodied, which may or may not be suitable for a new set of dancers. Roman explained that even though the casting process thoroughly considered individual personalities and attempted to match Juilliard dancers with appropriate counterparts from the original cast, the intention is to overlook specific characterizations and bring a new sense of individuality to the role:

Two of the students were adopting the character of Sang [Jijia], for example, and another was looking at the way Richard [Siegal] physicalized the material. It was a challenge for me, while I was showing somebody else something choreographically, to monitor how they were seeing and to see them absorb the characters from the original cast, rather than what they were doing, into their physical being. ${ }^{23}$ 
It is for this reason that Roman admitted that he prefers not to use video at all in a restaging process. Instead, he would rather teach the movement material and assign the improvisational tasks before the new cast has seen a recorded performance of the work. Part of Roman's job as the stager is to tailor an individualized version of the work for the specific dancers he has in front of him and to give them the version that works best for them and their particular physicalities. The video featured on Synchronous Objects represents just one possible version of the work, but it by no means should act as the only version. Before arriving at Juilliard, Roman re-familiarized himself with numerous versions of the work as it had been recorded on multiple occasions. Drawing on a number of performances, as well as on his own repertoire of embodied experiences, he was able to craft a version of the work that was suited to the Juilliard students. This method involves a complex editing process and hinges on Roman's ability to deconstruct the individual components of the work and then reconstruct them in a manner that is congruent with the overall ethos of the work and responsive to the talents of the new cast.

Because the Juilliard re-generation was the first time the work had been set by only one stager, Roman was forced to allow the video a more prominent role in the process than he would have liked. Due to the overwhelming density of the piece there was no way Roman would have been able to teach each of the individual roles in their entirety in the allocated time. So, the video was made available to the students from the very beginning and, in some ways, Roman utilized it as a sort of teaching assistant throughout the process. The students relied heavily on the video as well, and often they would arrive for rehearsals having already gone ahead and taught themselves the material as they saw it on the video. Though Roman recognized the ambition and professionalism 
that this showed on the part of the students, he admitted that he would regularly have to go back and have them unlearn that material for some reason. Most commonly, the students had taught themselves phrases of the dance that they had not realized were actually improvised. Although they were meant to be responding to the same improvisational tasks as the dancer on the video, the physical manifestation of those tasks was intended to represent the embodied response of each individual dancer as opposed to an imitation of the dancer on the screen. When asked about the experience of learning the material from video, the students agreed that they found it to be challenging at times. One student commented:

I think it was a hindrance because he gave us so much time to work on our own. When he was putting the piece together we all had so much time to go off and learn something by ourselves before we got to it. I think that because we just went to the video and learned everything we could, everything kind of became set in our heads. So, he has been chipping away at that, but in the beginning it was hard to get out of that because I was like, "I'm going do it like Ioannis [Mantafounis] because that's who I watched and how I got all my information."24

Another student agreed, "I learned step by step what he does in the video, so then to strip it down and start doing your own thing is difficult." ${ }^{25}$ The process of unlearning movement material is especially difficult once it has been inscribed into the dancer's muscle memory through embodied repetition. However, after Roman explained the choreographic structures and improvisational frameworks, the students were better able to understand how to incorporate their own physical choices into the tapestry of the work. 
For the students, learning $O F T r$ turned out to be more than just imitating the movement material and putting it all together on stage. Due to the complexity of the work, the process also involved learning to facilitate Forsythe's choreographic methodology and making impromptu decisions in response to the work's rigorous contrapuntal structure. Much of the improvisational material in $O F T r$ is designed to follow an extremely specific framework of reading the movements of other dancers in the space and, as one student explains, this reading enacts a constant negotiation between the movement material and the rest of the ensemble. One student commented, "I have a few moments where I am improvising and I could be reading anyone in the room at those times, so what I'm reading changes depending on who I'm even looking at, not only what those individuals are doing." ${ }^{26}$ At any point in the piece there may be multiple dancers working in this way, receiving their improvisational cues from the improvised material of others. This reciprocal continuity results in a work that is in a constant state of evolution and transformation, and it is for this reason that the concept of seeing in the moment, rather than seeing what is on the video, is of vital importance to the execution of the work..

From the outset of the restaging process, Roman made frequent and repeated references to the element of sight and its importance to the work. As the forward momentum of the piece hinges upon the dancers' execution of, and response to, predetermined cues, they must be constantly aware of what is going on around them in the space. This need for a keen sense of awareness is compounded by the fact that, when dancers are reading the movements of others to generate their own improvised responses, they are often working in unexplored territory with every performance of the work. 
When Roman referred to the element of dancers seeing one another in rehearsals, he often coupled it with an explanation of the ways in which the overall ecology of the piece functions as a result of the dancers' ability to see each other at all times. He made comments such as, "it is important to look around in this piece"27 and "the communication is equally as important as the dynamics of the movement." ${ }^{28}$ It was early in the process, during the fourth rehearsal, when Roman noted, "this is the first time I think you've realized that you can't do this alone." 29 He was referring to the sense of collaboration that is required to perform this piece, a reality that presented itself late in the rehearsal process when two of the dancers got injured. The fact that these injuries occurred just over a week before the scheduled performance left the entire ensemble shaken. They were clearly concerned for their peers, but there was also an overwhelming sense of tension as the group realized the importance of every individual dancer's role in the work; it actually cannot function with missing dancers because of the complex cueing system and interconnectedness of the dancers' relationships. The absence of the injured dancers caused the communication chain to break down because they could not deliver their cues. Subsequently, their roles had to be reallocated by slightly altering the choreography to accommodate the cues those dancers were to be giving. The realization that their individual roles were critical to the work became apparent in the students' comments. When asked about their personal views of what OFTr is about, many of the students' responses pertained to the cohesion and collaborative nature of the work. For example, one student said, "It's about trying to complete a task as a group, but doing things differently while still having to work as an organism that's vibrating all together. We are all doing different things, but we are all together, and we are trying to complete 
one thing by the end of it." ${ }^{30}$ In the case of $O F T r$, the ecology of the group that is so integral to the execution of the work is established through eye contact, watching and seeing one another in order to read the cues that propel the piece. Roman admitted that this is one element of the work that he feels gets lost in the video; he emphasized the importance of reiterating how crucial this eye contact is to the performance of the work:

I think what was missing that we had to keep backtracking on was the idea of ensemble. Because they were following the person in the purple shirt the whole time, and I was trying to teach them as we went along how to see the dance, how it was cued and when we'd go back and I'd go through all seventeen characters"let's just watch you" - and watch and tell them why they were moving and what their cues were... So the essence was really learning how to work as an ensemble and seeing what you're doing as you look to see what everybody else is doing and why it affects what you're doing and why you affect what they're doing. That was the essence of what they didn't get right away from having to learn it on the video, because they were just learning themselves. ${ }^{31}$

It was this essence of the work that Roman had to transmit through his own presence in the space. Through numerous verbal cues, he directed the students toward an understanding of the concept, but one of the most effective ways he communicated the energetic intention was through his own physicality. At numerous points throughout the process Roman captivated the students through his physical demonstrations, sharing information that gets lost in the video. In addition to the performative qualities that have been so deeply embedded in his kinesthetic memory through more than one hundred 
performances of the work, he retains an embodied repertoire of experience that he drew upon to facilitate an accurate re-generation of $O F T r$.

\section{Transmission Through Tactile-Kinesthetic Cues}

Operating beyond what is transmissible through demonstration and imitation, tactile cues are capable of evoking distinct kinesthetic sensibilities that can communicate a great deal about the work. As Tomie Hahn explains in her ethnographic study of learning the traditional Japanese dance nihon buyo, "the practice of learning through visual imitation, repetition, and close proximity to the teacher reinforces imprinting - a transference and

fixing of dance information in a student's physical memory." 32 What is important to this discussion is Hahn's reference to the student and teacher sharing a close proximal space to one another, where this intimate spatial relationship is likely to facilitate the transmission of tactile and kinesthetic cues.

It is important to differentiate between tactility and kinesthesia in order to understand the ways in which these two types of transmission functioned in the restaging of $O F T r$. Tactility refers directly to the sense of touch, and one's response to tactile feedback is generated through the proprioceptive assimilation of being touched. Tactile cues possess the unique ability to provide detailed information about the way it feels to touch and be touched — an important consideration, owing to the amount of partner work in OFTr. Throughout the piece, every dancer forms hundreds of tactile relationships with other dancers, the floor, and the tables. The amount of tactile information being fed back to the dancers at any given moment is overwhelming, and their physical responses to the tactile cues that emerge serve to add further dynamics to the work. The opening and closing scenes, where the dancers run while dragging the tables behind them, effectively 
punctuate the high level of tactility present throughout the piece and invite the audience directly into the experience by eliciting their innate kinesthetic response.

Both Susan Foster and Hahn refer to the viewer's sensory experience of watching dance as kinesthetic empathy. ${ }^{33}$ Hahn describes it as "an empathy rooted in the body that draws on kinesthesia - the sense that comprehends the body's weight, spatial orientation, and movement of muscles, tendons, and joints." 34 The rationale behind kinesthetic empathy is related to the neurological explanation of mirror neurons and suggests that, as humans, we have the ability to sense how others move and what they feel, so that, when we watch someone else dancing, we can empathetically internalize that sensation and, in a sense, experience what it feels like to perform the same movements. According to Hahn, such kinesthetic empathy "plays an important role in movement transference, in which a dancer, experiencing and physically identifying closely with the movements of a teacher, sympathetically coordinates her muscles to resemble the teacher's dance. The alignment between bodies via kinesthesia imprints movement and reinforces kinesthetic empathy for future lessons." 35 Acting in tandem with tactile feedback, kinesthetic empathy augments the visual components of demonstration and imitation by provoking a deeper sensorial relationship to the movement material that is being performed. Roman utilized both tactile and kinesthetic cues in the physical transmission of $O F T r$ and, by doing so, was able to facilitate sensorial experiences for the students.

Although, in the previous section, I discussed demonstration as a mode of visual transmission, it warrants further consideration here as a vehicle for fostering kinesthetic empathy. Roman's physical demonstration of movement phrases, modalities, and gestures offered much more than just a visual reference for the students to emulate. His 
corporeal execution of various elements of the work provided an interconnected network of cues for the students to read, interpret, and incorporate into their own embodied understanding of the material. Roman's frequent use of ballet vocabulary (as communicated through his bodily and verbal cues) served to enhance the students' ability to imitate his demonstrations, as they all shared a thorough knowledge of the lexicon to which he referred. For example, when Roman demonstrated an épaulement line or a rond de jambe, the students could immediately access that step from their own movement repertoire, thus enacting a sense of collective kinesthetic history across the group. In addition to providing a point of visual and kinesthetic reference for the students, Roman's demonstrations enabled the retrieval of his own embodied memories of the work. I observed many instances where Roman would watch a section on the video and then say "I have to get it in my body first," 36 before he was able to accurately teach the movement phrase to the students. This process of retrieval and re-familiarization through embodiment harkens back to the notion of corporeal inscription as it relates to the activation of muscle memory. Ethnographer Jaida Kim Samudra suggests, "we can record and translate kinesthetic experiences as they become memory in our body" ${ }^{\prime 37}$ and, in turn, the re-embodiment of those memories allows for the retrieval and re-activation of one's repertoire of kinesthetic experiences. Similarly, when the students returned to Juilliard after their spring break, they too experienced the retrieval of muscle memory through kinesthetic experience. Many of them admitted that even though they had not practiced the work during the break, as soon as they began to physically immerse themselves again in the rehearsal process, their bodies innately knew what to do. 
Another way that Roman facilitated the tactile-kinesthetic transmission of movement material was through his own physical participation at certain points in the rehearsal process. On numerous occasions, he would stand in for one of the dancers in order to explain how to perform a particular piece of the choreography. This strategy was most often used in partnering sections to demonstrate effective use of weight and correct body placement for the execution of lifts, although Roman also sometimes used his own body to work out the mechanical construction of complicated transitions onto and off the tables. This practice does more than simply demonstrate an action; it enacts a reciprocal kinesthetic experience that provides detailed sensory information about the timing, flow, and intent of a certain movement. As Hahn explains, "When someone/something contacts our body we can perceive its movement quality, such as the speed and direction of its action. For example, if someone takes your hand, swings, and releases it in an upward toss, you experience this arm gesture through touch. The energy, or force, of the tactile encounter imparted a speed and direction of motion to your body." ${ }^{38}$ In this way, Roman's physical transmission of sensory cues provided invaluable information to the dancers about the ways in which certain movements should feel, a sense that is not available through any other mode of documentation or transmission. Of course, visual demonstrations and verbal explanations can give clues about how a lift or partnering section should feel, but no other direction is as authentic as the actuality of sensing that lived experience kinesthetically. According to Hahn, "this full-bodied feature of the sense is ideal for dance transmission, where the entire (receptive) body can feel and mediate movement qualities." ${ }^{39}$ Although tactile-kinesthetic transmission is an integral part of any re-generation process, the complex web of interconnections and relationships in $O F T r$ 
provides a clear example for interrogating its use as a mode of communicating essential information specific to the dance. The speed at which the piece unfolds, as well as the intricate cuing system and precarious placement of the tables, all contribute to the heightened sensory awareness that is required to perform the work. Roman's extensive experience as a dancer in $O F T r$ undeniably contributed to the apparent ease with which he was able to physically guide the students through their intricate negotiations with all of the work's elements.

\section{Transmission Through Directive, Intentional, Referential, and Metaphorical Verbal Cues}

My first instinct on beginning this research was to assume the priority of visual cues over any others when attempting to determine the efficacy of various modes of transmission in the restaging process. I have since discovered that in this case study Roman's deployment of verbal communication proved to be irreplaceable. In truth, this should not be surprising, considering the variety of traditions that rely primarily on oral history to share dances, as evidenced by the ethnographic research of scholars such as Hahn, Janet O’Shea and Jacqueline Shea Murphy. ${ }^{40}$ However, the somewhat tenuous relationship between dance and language has provoked some doubt as to whether linguistic signifiers can be used to accurately describe movement. Both Gay Morris and Sally Ann Ness have challenged the long-standing assumption that language is capable of communicating an authentic description of movement and gesture. Morris asks, "what is dance's relationship to language and is it possible to deconstruct the dichotomy between mind and body that has worked to dance's disadvantage for so long?"41 At the root of Morris's query is the reality that dance has traditionally been trivialized by theories that equate 
value with linguistic description. Similarly, Ness suggests, "dance was often cast in oppositional terms as the 'nonverbal' medium of communication. This implicitly positioned dance as an inferior medium, a relatively primitive counterpart to language." ${ }^{22}$ Conversely, scholars such as Friedman and Hahn suggest that language, shared through oral/aural transmission, is capable of illuminating meta-narratives that can augment and enhance the communicative powers of dance. Friedman argues that, through oral history, "we have a chance to reveal alternatives considered, but not taken, revealing the full three-dimensional humanity of historical action." ${ }^{\text {43 }}$ Likewise, Hahn explains, "I found that teachers' articulations in lessons form a meta-language, a unique dance instructional language reflecting a varied and deeply complex matrix of information." ${ }^{24} \mathrm{My}$ observations echoed those of Hahn and unveiled multiple ways in which verbal cuing proved to dramatically enhance the transmission process.

While restaging $O F \operatorname{Tr}$ Roman utilized verbal cues in a number of different ways that I have classified as directive, intentional, referential, and metaphorical. Directive cues refer to uses of language that indicated to the students what should be happening at any given moment, when and where the action was to take place, and who was involved in the particular activity. In essence, directive language was quite literally intended to direct the construction of the choreography, and it was often used as the first point of departure in explaining how the work fit together. For instance, Roman often utilized directive language when the group was watching the video of the section they were about to construct. He would explain to the students exactly what was happening in the video with a commentary to the effect of, "see, there's Cyril [Baldy] and that roll on the floor is the cue for Fabrice [Mazliah] and Yoko [Ando] to enter the space." ${ }^{45}$ Then, when the 
group moved to the tables to piece the section together, Roman's verbal cues directed the formation of the choreographic structure with instructions such as, "grab back of right hand with palm of left" and "use left arm to push off." extremely specific, and often related to precise anatomical, spatial, and temporal configurations. The use of directive cues allowed Roman to relay information about the structural foundation of the work with relative ease and efficiency. For the students, the directive information they received provided a clear verbal counterpart to the visual clues about the structure they were able to see on the video.

Differing slightly from directive instructions, intentional cues were employed by Roman to explain why certain elements of the work are necessary. Operating on a broader conceptual level, intentional cues conveyed information about the governing principles of the work, such as the functionality of the internal cuing system and the choreographic design of the work's contrapuntal structure. The most important intentional cue Roman communicated was the explanation that the dance operates as a task-oriented challenge. It was vital for the students to understand that the movement material in $O F T r$ is not intended to be movement for movement's sake, but that there is an evolving, fluctuating system of interconnected tasks that actually drives the momentum of the dance forward.

Intentional language was also used when directing the students in their improvisational tasks. Roman explained to the dancers that the intention of the task is to see what another body in the space is doing and to interpret its actions through your embodiment of the phrase; in other words, "to see the body part and make decisions in relation to it." ${ }^{\prime 47}$ Without a detailed explanation of the precise rules governing the improvisations they were intended to follow, the students would have struggled to decode 
that information from the visual clues evident on the video. Unlike the directive cues, which tended to be more prevalent in the early stages of rehearsal, intentional cues continued to be verbalized throughout the duration of the process. Roman constantly reiterated the most integral intentional concept, which was the necessity for the dancers to continue looking at one another and to really see what they were doing. At one point he described the importance of seeing each other as "a communicative dialogue between the ranks of the working group - the communication is equally as important as the dynamics of the movement." ${ }^{48}$ Though Roman was referring to the visual and kinesthetic communication that occurs among the dancers on stage, his explanation could also be applied to the restaging process on a broader level. The verbal dialogue that Roman employed throughout the re-generation of $O F T r$ proved to be equally important to the transmission of movement material through other modes of sensorial communication.

Of vital importance to the restaging of $O F T r$ were the ways in which Roman used language to elicit the particular corporeal execution of certain elements of the work. He employed the use of referential and metaphorical linguistic cues to guide the students about how to embody specific movement material. Referential cues were used to draw comparisons between desired movement qualities through external references that did not necessarily pertain directly to the work. In other words, they provided a variety of contextual lenses through which the dancers could consider their approach toward the movement material. Roman used a range of culturally specific referential cues when describing both desirable and undesirable movement qualities and stylistic embellishments. For example, he often advised the students against adopting the nuances of other movement vocabularies with comments such as "no Martha Graham pleadings"49 
or “don't get Baroque." ${ }^{.50}$ On one occasion he referred to the students' classical ballet training and said, "it's very Cecchetti, head to the working leg"51 to describe the relationship between a tendu and the eye focus in one particular section. These verbal cues proved to be highly effective because they related directly to the collective kinesthetic history of the dancers, and would not have been applicable had the group not possessed a shared cultural understanding of those references.

In addition to the culturally specific references the group had in common, they developed their own lexicon of referential cues throughout the process, which became adopted as universally understood terms among participants. As the thematic material became inscribed and the work took choreographic shape, Roman and the dancers began to refer to specific moments in the dance through their own colloquial language. For instance, phrases of thematic material acquired referential labels such as "duckie" and "Fab dance," and various sections of the work were referred to by directive terms such as "sit-up" and "reset." When Roman asked the dancers to begin the material at the "reset" section, they all knew what he meant and would proceed directly to their starting positions. In this way, referential cuing acted as a sort of short-hand instructional language that would have seemed odd to anyone not privy to its ascribed meaning.

Adding a further layer to the concept of how the dancers were guided to execute the material, Roman used metaphorical language and imagery to elicit certain performative responses. By traditional definition, "metaphor is a matter of words, not thought. Metaphor occurs when a word is applied not to what it normally designates, but to something else." ${ }^{.52}$ When perceived in this way, metaphorical language can be employed to facilitate a unique process of embodiment for dancers that is referential to an 
object or experience with no apparent relevance to the work itself. It enables opportunities to explore kinesthetic relationships among movement, language, and one's repertoire of experiences. According to Sondra Fraleigh, the use of metaphorical language and imagery is integral to the process of restaging an existing work:

In order to reconstruct or to dance another choreographer's work, a dancer strives to recreate the choreographer's aesthetic intentions - to embody them in performance. Thus the imagery that brings out the aesthetic intent of the dancewhether it is focused in qualitative properties of movement or designed to project, represent, or symbolize something else through movement—is crucial to the dancer's understanding. ${ }^{53}$

The use of metaphorical language and imagery cues pervades dance practice and discourse in the areas of pedagogy and somatics, but it has rarely been interrogated for its role in restaging choreographic works. Yet my observations at Juilliard showed its efficacy as a communicative tool. Metaphorical language appeared to be most useful when refining the movement quality and performative subtleties. Roman used images such as a "helicopter," "Egyptian hieroglyphics," and "corkscrewing" to evoke particular movement qualities from the dancers. In this case, where the participants shared similar cultural and experiential backgrounds, this type of metaphorical cuing evoked similar interpretations, apparently reflecting a common understanding of the individual dancer's perception of the image. However, in situations where the cultural identities of the participants are more diverse, the potential for misinterpretation of metaphorical language cues is bound to become an underlying consideration. One of the advantages of verbal communication in this instance was that Roman's presence in the space allowed for a 
reciprocal dialogue between him and the students. If there happened to be any confusion, it was settled immediately through a verbal exchange. Many of the students identified this verbal reciprocity as an integral part of the process. One student explained, "There are times when you have a whole piece in front of you on a screen and you see it and you still don't really know what's going on, and having someone who does, who can explain it, is invaluable. You couldn't replace the human in the room." ${ }^{54}$ Another student mentioned the importance of being guided by "a leader who is knowledgeable and who you can really trust and listen to and ask questions of," personal experience from someone that was in the original cast is such a wonderful learning tool. ${ }^{956}$ When asked about their experience of learning $O F T r$ through the combined information from Synchronous Objects and Roman's personal experience, one student responded, "that's the scary thing — that even with such a thorough form of notation, without an almost immediate source, you still wouldn't know the answer." 57 Of course, although visual, tactile, kinesthetic, and verbal modes of transmission have been discussed here in isolation, they by no means acted independently from one another in the Juilliard case study. Throughout the re-generation process, visual, tactile, and verbal cues were constantly presented as a complex web of sensory information. Roman's role, as the stager, was to deliver as much information in as many ways as possible, and it then became the students' responsibility to assimilate and learn to embody those cues. In a comparison between organized sport and music, Maxine SheetsJohnstone suggests, "like the rules of the game, the musical performances of others and the actual notes on the musical score sheet constrain but do not limit creativity." ${ }^{\prime 58}$ This notion can similarly be applied to $O F T r$ as the score, the video recording, or the 
choreographic directives and improvisational tasks, as originally set by Forsythe, each form a conceptual framework within which the work can function. The choreographic rules establish a structure that facilitates play among the dancers, while also leaving open a seemingly liminal space between concept and corporeal execution, a place where the dancing body itself acts as a site of knowledge re-generation, preservation, and translation, a living site upon which to inscribe and preserve the kinesthetic history of a work.

My observations confirmed that kinesthetic history provides a valuable methodological approach toward both the apprehension and transmission of a complex choreographic design. The sensorial experience of sharing $O F T r$ through visual, tactile, kinesthetic, and verbal cues enabled a transmission process that most closely resembled the initial act of choreographic inscription, and therefore suggests a logical coherence of practice. Furthermore, the reliance on human interaction, reciprocal dialogue, and kinesthetic collaboration allowed for the work to fluctuate in response to the next generation of subjective agents whose bodies came to bear the mark of the work.

Finally, when considering Forsythe's own fascination with the idea of failure, and how that theme is embedded within much of his choreographic process, we can, perhaps, borrow his use of the term "failure" as another lens through which to view re-generation. Perhaps we should embrace the notion of failure, as Forsythe does, and for our purposes here, accept that failure to reproduce the work exactly as it once was is actually a sign of achievement. Failure to reproduce a fixed object, failure to achieve an exact replication of a work, and failure to duplicate a past performance actually substantiate the idea that failure fosters re-generation. Failure to be something other than what it once was and 
failure to fetishize the work as a tangible object actually achieve Forsythe's overall goal, which is for the continuous development of his works.

To conclude, this research illustrates how the introduction of a new generation of cast members into the re-staging of a choreographic work weaves a colorful tapestry of the work's historical kinesthetic experiences into present collaborative embodied experiences. Furthermore, the re-generation of $O F T r$ supports Taylor's concept of the repertoire:

Performances also replicate themselves through their own structures and codes. This means that the repertoire, like the archive, is mediated. The process of selection, memorization or internalization, and transmission takes place within (and in turn helps constitute) specific systems of re-presentation. Multiple forms of embodied acts are always present, though in a constant state of againness. They reconstitute themselves, transmitting communal memories, histories, and values from one group/generation to the next. Embodied and performed acts generate, record, and transmit knowledge. ${ }^{59}$

In this way, the term re-generation underscores the continuous evolution of dance works and provides opportunities to revisit and reinscribe the existence of the work in ways that evolve from the individual bodies that perform and reperform it. Each generation of the work is created anew, and is representative of the ever-changing negotiation that exists between historical records and past performances. The liminal space between score, screen, and stage is not only an active space, but also an interactive space. It is a space that may be intangible, but not unintelligible. It is a space where perception, interpretation, and experimentation provide opportunity to challenge our pre-existing 
beliefs about what it means to preserve contemporary dance. No longer is it necessary to objectify the written score as tangible evidence of fact, or fetishize the images we see on screen as visual representations of truth. These records will never achieve the entirety of a dance, because entirety would mean that the dance is complete, which is not the goal. Instead, this research recognizes the opportunities offered by the various modes of documentation that act as lenses through which to consider the ways that the kinesthetic history of moving bodies activates and re-generates the liminal spaces between score, screen, and stage, providing an opportunity to re-generate the future, rather than historicize the past.

\section{NOTES}

${ }^{1}$ Marcia Siegel, At the Vanishing Point: A Critic Looks at Dance (New York: Saturday Review Press, 1972), 1.

${ }^{2}$ See, for example, Lynn Matluck Brooks and Joellen A. Meglin, eds., Preserving Dance Across Time and Space (London: Routledge, 2013); Stephanie Jordan, ed., Preservation Politics: Dance Revived, Reconstructed, Remade (London: Dance Books Ltd., 2000); Douglas Rosenberg, Screendance: Inscribing the Ephemeral Image (New York: Oxford University Press, 2012).

${ }^{3}$ Jeff Friedman, "Muscle Memory: Performing Oral History," Oral History, vol. 33, no. 2 (2005): 35 .

${ }^{4}$ Gabriele Brandstetter, "Choreography as a Cenotaph: The Memory of Movement," ReMembering the Body (Ostfildern, Germany: Hatje Cantz Publishers, 2000),102-34;

Tomie Hahn, Sensational Knowledge: Embodying Culture through Japanese Dance 
(Middletown, CT: Wesleyan University Press, 2007);.Sally Ann Ness, "The Inscription of Gesture: Inward Migrations in Dance," in Migrations of Gesture, ed. Carrie Noland and Sally Ann Ness (Minneapolis, MN: University of Minnesota Press, 2008), 1-30.

${ }^{5}$ Susan Leigh Foster, Choreographing Empathy: Kinesthesia in Performance (London: Routledge, 2011), 28.

${ }^{6}$ Stuart Hodes, "Dance Preservation and the Oral History Paradigm" in Dance Reconstructed: A Conference on Modern Dance Art Past, Present, and Future, ed. Barbara Palfy (New Brunswick, NJ: Rutgers University Press, 1992), 97.

${ }^{7}$ Valerie Preston-Dunlop and Lesley-Anne Sayers, "Gained in Translation: Recreation as Creative Practice," Dance Chronicle, vol. 34, no. 1 (2011): 12.

${ }^{8}$ Ibid., $14-15$.

${ }^{9}$ Brandstetter, "Choreography as Cenotaph," 104.

${ }^{10}$ Diana Taylor, The Archive and the Repertoire (Durham, NC: Duke University Press, 2003), 16.

${ }^{11}$ Ibid., 20.

${ }^{12}$ Ibid., 20.

${ }^{13}$ Sally Ann Ness, "Dancing in the Field: Notes from Memory,"in Corporealities:

Dancing, Knowledge, Culture, and Power, ed. Susan Foster (New York: Routledge, 1996), 133-58.

${ }^{14}$ Ibid., 141.

${ }^{15}$ Ness, "The Inscription of Gesture," 5.

${ }^{16}$ Ibid., 6.

${ }^{17}$ Brandstetter, "Choreography as Cenotaph," 104. 
${ }^{18}$ Dance Heritage Coalition, "Beyond Memory: Preserving the Documents of Our

Dance Heritage,"

http://new.danceheritage.org/html_OLD/preservation/beyond.html\#intro (accessed April

21, 2015).

19 Taylor, The Archive and the Repertoire, 20.

${ }^{20}$ Ibid., 20.

${ }^{21}$ William Forsythe, "Synchronous Objects: The Dance," accessed March 15, 2013, http://synchronousobjects.osu.edu

${ }^{22}$ Christopher Roman, Associate Artistic Director of The Forsythe Company, in discussion with the author, March 22, April 6, and August 14, 2013.

${ }^{23}$ Ibid.

${ }^{24}$ Juilliard dance students in discussion with the author, March 21-27, 2013.

${ }^{25}$ Ibid.

26 Ibid.

${ }^{27}$ Author's field notes, February 12, 2013.

${ }^{28}$ Ibid., February 7, 2013.

${ }^{29}$ Ibid.

${ }^{30}$ Juilliard dance students in discussion with the author.

${ }^{31}$ Christopher Roman, in discussion with the author.

${ }^{32}$ Hahn, Sensational Knowledge, 83.

${ }^{33}$ Foster, Choreographing Empathy.

${ }^{34}$ Hahn, Sensational Knowledge, 84.

${ }^{35}$ Ibid. 
${ }^{36}$ Author's Field Notes, Feb 14, 2013.

${ }^{37}$ Jaida Kim Samudra. "Memory in Our Body: Thick Participation and the Translation of Kinesthetic Experience," American Ethnologist, vol. 35, no. 4 (2008): 678.

${ }^{38}$ Hahn, Sensational Knowledge, 101.

${ }^{39}$ Ibid., 100.

${ }^{40}$ Jacqueline Shea Murphy, The People Have Never Stopped Dancing (Minneapolis, MN:

University of Minnesota Press, 2007); Janet O'Shea, At Home in the World: Bharata

Natyam on the Global Stage (Middletown, CT: Wesleyan University Press, 2007).

${ }^{41}$ Gay Morris, ed., Moving Words: Re-writing Dance (New York: Routledge, 1996), 2.

${ }^{42}$ Ness, "The Inscription of Gesture," 7.

${ }^{43}$ Friedman, "Muscle Memory," 36.

${ }^{44}$ Hahn, Sensational Knowledge, 119.

${ }^{45}$ Author's field notes, February 4, 2013.

${ }^{46}$ Ibid.

${ }^{47}$ Ibid., March 18, 2013.

${ }^{48}$ Ibid., February 7, 2013.

${ }^{49}$ Ibid., February 4, 2013

${ }^{50}$ Ibid., March 25, 2013

${ }^{51}$ Ibid., February eb 19, 2013.

${ }^{52}$ George Lakoff and Mark Johnson, Metaphors We Live By (Chicago, IL: The University of Chicago Press, 1980), 119.

${ }^{53}$ Sondra Horton Fraleigh, Dance and the Lived Body: A Descriptive Aesthetics

(Pittsburgh, PA: University of Pittsburgh Press, 1987), 210. 
${ }^{54}$ Juilliard dance students in discussion with the author.

${ }^{55}$ Ibid.

${ }^{56}$ Ibid.

57 Ibid.

${ }^{58}$ Maxine Sheets-Johnstone, "Tactile-Kinesthetic Bodies: Ontogenetical Foundations of Apprenticeship Learning," Human Studies, vol. 23, no. 4 (October 2000): 359.

59 Taylor, The Archive and the Repertoire, 20-21. 